\title{
The Influence of Substituents on the Tautomerism of Symmetrically Substituted 2,2'-Bis- benzimidazoles
}

\author{
Evandro Dall'Oglio ${ }^{a}$, Miguel B. Caro ${ }^{a}$, José C. Gesser ${ }^{a}$, César Zucco ${ }^{* a}$ and Marcos C. Rezende \\ ${ }^{a}$ Departamento de Química, Universidade Federal de Santa Catarina, CP 476, 88040-900, Florianópolis - SC, Brazil \\ ${ }^{b}$ Facultad de Química y Biología, Universidad de Santiago de Chile, Casilla 40, Correo 33, Santiago, Chile
}

O tautomerismo de cinco 2,2'-bis-benzimidazóis, simetricamente substituídos, [5(6),5'(6')tetrametil-(1); 5(6),5'(6')-dimetil-(2); 5(6),5'(6')-dicloro- (3); 5(6),5'(6')-dimetoxi- (4) e 4(7),4'(7')dimetil-2,2'-bis-benzimidazol (5)], foi estudado por espectroscopia de ${ }^{1} \mathrm{H}$ RMN, a várias temperaturas, e a influência dos substituintes nas barreiras energéticas de interconversão tautomérica, interpretada através de cálculos teóricos.

The tautomerism of five symmetrically substituted 2,2'-bis-benzimidazoles [5(6),5'(6')tetramethyl-(1); 5(6),5'(6')-dimethyl-(2); 5(6),5'(6')-dichloro- (3); 5(6),5'(6')-dimethoxy- (4) and 4(7),4'(7')-dimethyl-2,2' -bis-benzimidazole (5)], was studied by means of ${ }^{1} \mathrm{H}$ NMR spectroscopy at variable temperatures, and the influence of the substituents on the energy barriers for tautomeric interconversion was interpreted with the aid of theoretical calculations.

Keywords: bis-benzimidazoles, tautomerism, dynamic NMR

\section{Introduction}

We have recently investigated the tautomerism of 2,2'bis-benzimidazole in DMSO- $\mathrm{d}_{6}$ through analysis of its ${ }^{1} \mathrm{H}$ NMR spectra at various temperatures, ${ }^{1}$ due to our interest in developing synthetic methodologies targeting these compounds. ${ }^{2,3}$ The tautomeric interconversion barrier for this class of compounds was estimated to be $67 \mathrm{~kJ} \mathrm{~mol}^{-1}$.

The postulated mechanism essentially agreed with that proposed for the tautomerization of oxalamidines ${ }^{4-6}$ and related systems, ${ }^{7}$ which involves a stepwise proton shift and formation of intermediate dipolar species. This proton shift is accompanied by a heavy-atom reorganization of the whole molecule. The evidence for such a mechanism stemmed from isotope NMR experiments, coupled with theoretical calculations.

In continuation of our interest in this subject, we decided to investigate the substituent influence on the tautomeric barriers of 2,2'-bis-benzimidazoles in solution. In contrast with related imidazole ${ }^{8,9}$ and benzimidazole ${ }^{10}$ systems, whose tautomeric processes have been studied theoretically, there are no reports on the tautomerism of substituted bis-benzimidazoles.

\footnotetext{
*e-mail:czucco@qmc.ufsc.br
}

In this paper we present the results of ${ }^{1} \mathrm{H}$ NMR studies at various temperatures of five symmetrically substituted 2,2'-bis-benzimidazoles: 5(6),5'(6')-tetramethyl- (1); 5(6),5'(6')-dimethyl- (2); 5(6),5'(6')-dichloro- (3); 5(6), 5'(6')-dimethoxy- (4) and 4(7),4'(7')-dimethyl-2,2'-bisbenzimidazole (5).

The corresponding barriers for tautomeric interconversions were calculated from the spectral variations at different temperatures and the results were interpreted by means of theoretical calculations employing the PM3 semi-empirical method.

\section{Experimental}

The substituted bis-benzimidazoles were prepared by sonication of a solution of hexachloroacetone and the corresponding substituted $o$-phenylenediamine in ethylene glycol. ${ }^{11}$ The ${ }^{1} \mathrm{H}$ NMR spectra of all 2,2'-bisbenzimidazoles prepared under conditions of fast exchange (N-H protons not discernible) and results of the microanalyses were as follows (chemical shifts are given in ppm): 1: $\delta 2.45\left(\mathrm{~s}, 12 \mathrm{H}, \mathrm{CH}_{3}\right) ; 7.48(\mathrm{~s}, 4 \mathrm{H}, \mathrm{Ar}-\mathrm{H})$. Anal. calcd. for $\mathrm{C}_{18} \mathrm{H}_{18} \mathrm{~N}_{4}$ : C, 74.46; H, 6.25; N, 19.30 . Found: C, 74.23; H, 6.10; N, 19.18\%. MS: $m / z 52$ (6.60), 65 (11.00), 77 (10.00), 91 (13,19), 116 (6.60), 130 (16.48), 137 (17.58), 145 (18.70), 275 (27.47), 290 (100); 2: $\delta$ 
<smiles>Cc1cc2nc(-c3nc4cc(C)c(C)cc4[nH]3)[nH]c2cc1C</smiles>

(1)<smiles>[X]c1ccc2[nH]c(-c3nc4cc([X])ccc4[nH]3)nc2c1</smiles>

$\mathrm{X}=\mathrm{Me} \quad$ (2)

$\mathrm{X}=\mathrm{Cl}$

$\mathrm{x}=\mathrm{OMe}(4)$

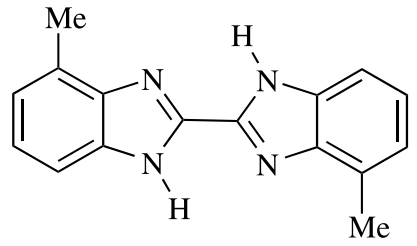

(5)

Scheme 1.

$2.47\left(\mathrm{~s}, 6 \mathrm{H}, \mathrm{CH}_{3}\right) ; 7.10$ (d, $\left.2 \mathrm{H}, J 8.2 \mathrm{~Hz}, \mathrm{Ar}-\mathrm{H}\right) ; 7.47$ (s, 2 $\mathrm{H}, \mathrm{Ar}-\mathrm{H})$; 7.55 (d, 2H, J 8.2 Hz, Ar-H). Anal. calcd. for $\mathrm{C}_{16} \mathrm{H}_{14} \mathrm{~N}_{4}$ : C, 73.28; H, 5.34; N, 21.37. Found: C, 73.20; H, 5.23; N, 21.32\%. MS: $m / z(\%) 52$ (15.40), 77 (26.40), 104 (9.90), 130 (27), 156 (12.08), 261 (62.64), 262 (100); 3: $\delta 7.31$ (d, 2 H, J 8.2 Hz, Ar-H); 7.72 (br s, 4 H, Ar-H). Anal. calcd. for $\mathrm{C}_{14} \mathrm{H}_{8} \mathrm{Cl}_{2} \mathrm{~N}_{4}: \mathrm{C}, 55.45 ; \mathrm{H}, 2.64 ; \mathrm{N}, 18.48$. Found: C, 55.32; H, 2.52; N, 18.41\%. MS: $\mathrm{m} / \mathrm{z}(\%) 52$ (7.70), 63 (28.57), 90 (12.09), 124 (15.38), 152 (17.58), 177 (17.40), 268 (9.90), 302 (100), 303 (20.87), 304 (64.83), 305 (12.09); 4: $\delta 3.85$ (s, $6 \mathrm{H}, \mathrm{OMe}) ; 6.90$ (dd, 2 H, J 8.8 Hz, J' 2.2 Hz, Ar-H); 7.14 (d, 2 H, J 2.2 Hz); 7.54 $(\mathrm{d}, 2 \mathrm{H}, J 8.8 \mathrm{~Hz})$. Anal. calcd. for $\mathrm{C}_{14} \mathrm{H}_{14} \mathrm{~N}_{4} \mathrm{O}_{2}: \mathrm{C}, 65.31$; H, 4.76; N, 19.05. Found: C, 65.02; H, 4.58; N, 18.91\%. MS: $m / z(\%) 52$ (19.80), 65 (11), 77 (14.30) 91 (5.50), 147 (24.17), 236 (14.28), 251 (31.87), 279 (75.82), 294 (100); 5: $\delta 2.65$ (s, $\left.6 \mathrm{H}, \mathrm{CH}_{3}\right) ; 7.07$ (d, $\left.2 \mathrm{H}, J 7.2 \mathrm{~Hz}\right) ; 7.18$ (t, $2 \mathrm{H}, J 7.2 \mathrm{~Hz}) ; 7.50(\mathrm{~d}, 2 \mathrm{H}, J 7.2 \mathrm{~Hz})$. Anal. calcd. for $\mathrm{C}_{16} \mathrm{H}_{14} \mathrm{~N}_{4}$ : C, 73.28; H, 5.34; N, 21.37. Found: C, 73.14; H, 5.18; N, 21.30\%. MS: $m / z(\%) 52$ (14.29), 77 (21.98), 104 (9.90), 130 (30.77), 156 (10.00), 261 (61.54), 262 (100.00).

The ${ }^{1} \mathrm{H}$ NMR spectra were recorded with a Bruker AC200 spectrometer, employing TMS as an internal reference and a mixture of DMSO- $\mathrm{d}_{6} / \mathrm{Me}_{2} \mathrm{CO}-\mathrm{d}_{6}(1: 4)$ as the solvent. Temperature control of the samples was achieved by calibrating the high temperature range (300-400 K) with ethylene glycol and the low temperature range (170-300 K) with methanol, following techniques described by Bruker in the Variable Temperature Unit, B-VT 2000, Manual. Before recording the NMR spectra of each sample at a specific temperature, the preset temperature was corrected according to the observed chemical shifts of $80 \%$ ethylene glycol in DMSO- $\mathrm{d}_{6}$ and $4 \%$ methanol in methanol- $\mathrm{d}_{6}$. Spectra were preliminarily recorded at various temperatures, with $10 \mathrm{~K}$ intervals. Near the coalescence temperatures this interval was reduced to $1 \mathrm{~K}$.

\section{Calculations}

Calculations in the gas phase and in solution were performed with the COSMO option ${ }^{12}$ of MOPAC 97.0.

Full geometrical optimizations of the substrates and intermediates were carried out employing the PM3 hamiltonian and the eigenvector-following (EF) method of convergence. The determination of the transition state geometries was achieved by employing a transition-statesearch (TS) routine, starting from different initial geometries which, in all cases, converged to the same structure. In addition, a FORCE calculation was performed for all putative ground- and transition-states. In the case of substrates and intermediates, all obtained structures exhibited only positive vibrations. Transition-state structures exhibited, besides all normal positive modes, only one imaginary vibration around $2180 \mathrm{~cm}^{-1}$, comprising the proton-in-flight $\mathrm{N}-\mathrm{H}$ vibrations.

\section{Results}

\section{Spectroscopic results}

The simplest system investigated was compound 1, which yielded at $313 \mathrm{~K}$ one singlet at $\delta 7.41$ for the equivalent aromatic protons $\mathrm{H}_{\mathrm{a}}$. Below a coalescence 
<smiles>[2H]c1c(C)c(C)c(C)c2[nH]c(-c3nc4c(C)c(C)c(C)c([Hg])c4[nH]3)nc12</smiles>

Scheme 2.

temperature of $303 \mathrm{~K}$, this signal splits into two singlets of equal intensity, at $\delta 7.35$ and 7.55 , exchanging slowly at $233 \mathrm{~K}$. These two singlets arise from the tautomeric equilibrium shown below, with two nonequivalent protons $\mathrm{H}_{\mathrm{a}}$ and $\mathrm{H}_{\mathrm{a}}$. The whole process is illustrated in Figure 1.

The spectrum of compound 2 at $323 \mathrm{~K}$ presented a doublet at $\delta 7.10$, corresponding to $\mathrm{H}_{\mathrm{c}}$, one singlet at $\delta$ 7.47 , ascribed to $\mathrm{H}_{\mathrm{a}}$, and another doublet at $\delta 7.55$, due to $\mathrm{H}_{\mathrm{b}}$. This pattern was still clearly discernible at $308 \mathrm{~K}$ (Figure 2a).The latter doublet coalesced at $297 \mathrm{~K}$ (Figure 2b). A second coalescence took place at $287 \mathrm{~K}$, corresponding to the $\mathrm{H}_{\mathrm{c}}$ doublet. At $258 \mathrm{~K}$ the presence of the two tautomers in slow equilibrium could be deduced from the obtained spectrum: The $\mathrm{H}_{\mathrm{c}}$ doublet split into two adjacent doublets, centered at $\delta 7.12$ and 7.16. The $\mathrm{H}_{\mathrm{b}}$ doublet was likewise split into two adjacent doublets, centered at $\delta 7.61$ and 7.65. The $\mathrm{H}_{\mathrm{a}}$ singlet was split into two signals, a singlet at $\delta 7.40$ and a doublet centered at $\delta 7.47$. The variations with temperature are reproduced in the expanded spectra of Figure 2 and the process is interpreted by the tautomeric equilibrium below, which applies also to compounds 3 and 4.

The behaviour of the $\mathrm{H}_{\mathrm{a}}$ singlet at low temperature is interesting. Of the two signals arising from the nonequivalent $\mathrm{H}_{\mathrm{a}}$ and $\mathrm{H}_{\mathrm{a}}$, protons, one of them $\left(\mathrm{H}_{\mathrm{a}}\right.$ ) was further split by the adjacent $\mathrm{N}-\mathrm{H}$ proton, which also appeared as a doublet (not shown) at $\delta 13.60$ at $258 \mathrm{~K}$.

The spectrum of the dichlorobis-benzimidazole $(3)$ at $297 \mathrm{~K}$ (Figure 3a) showed a doublet at $\delta 7.31$, corresponding
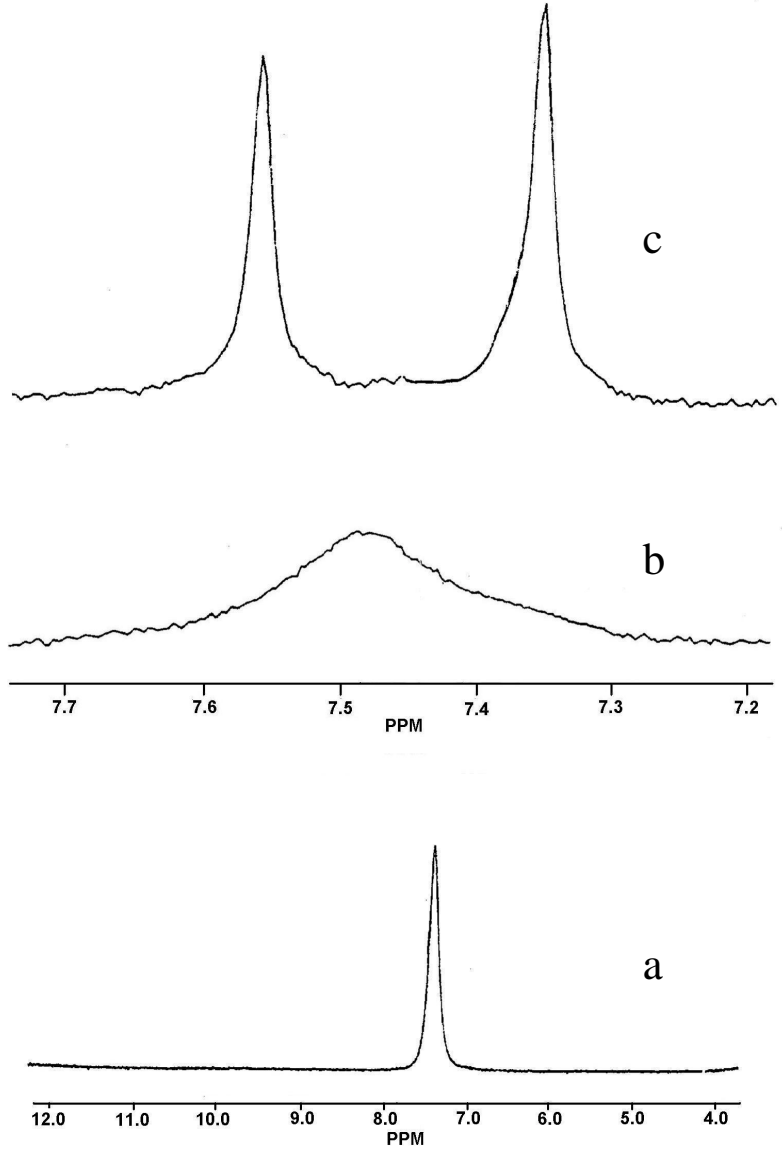

Figure 1. NMR spectra of compound 1 in DMSO- $\mathrm{d}_{6} / \mathrm{Me}_{2} \mathrm{CO}-\mathrm{d}_{6}$ at different temperatures. Evolution of the aromatic protons at (a) 313 $\mathrm{K}$; (b) $303 \mathrm{~K}$; (c) $233 \mathrm{~K}$<smiles>[X]c1ccc2[nH]c(-c3nc4c([2H])c([X])c([2H])c([2H])c4[nH]3)nc2c1[2H]</smiles><smiles>[X]c1cc2nc(-c3nc4c(C)c([2H])c([X])c(C)c4[nH]3)[nH]c2cc1[X]</smiles>

$\mathrm{X}=\mathrm{Me}(\mathbf{2})$

$\mathrm{X}=\mathrm{Cl}$

$\mathrm{x}=\mathrm{OMe}(\mathbf{4})$ 

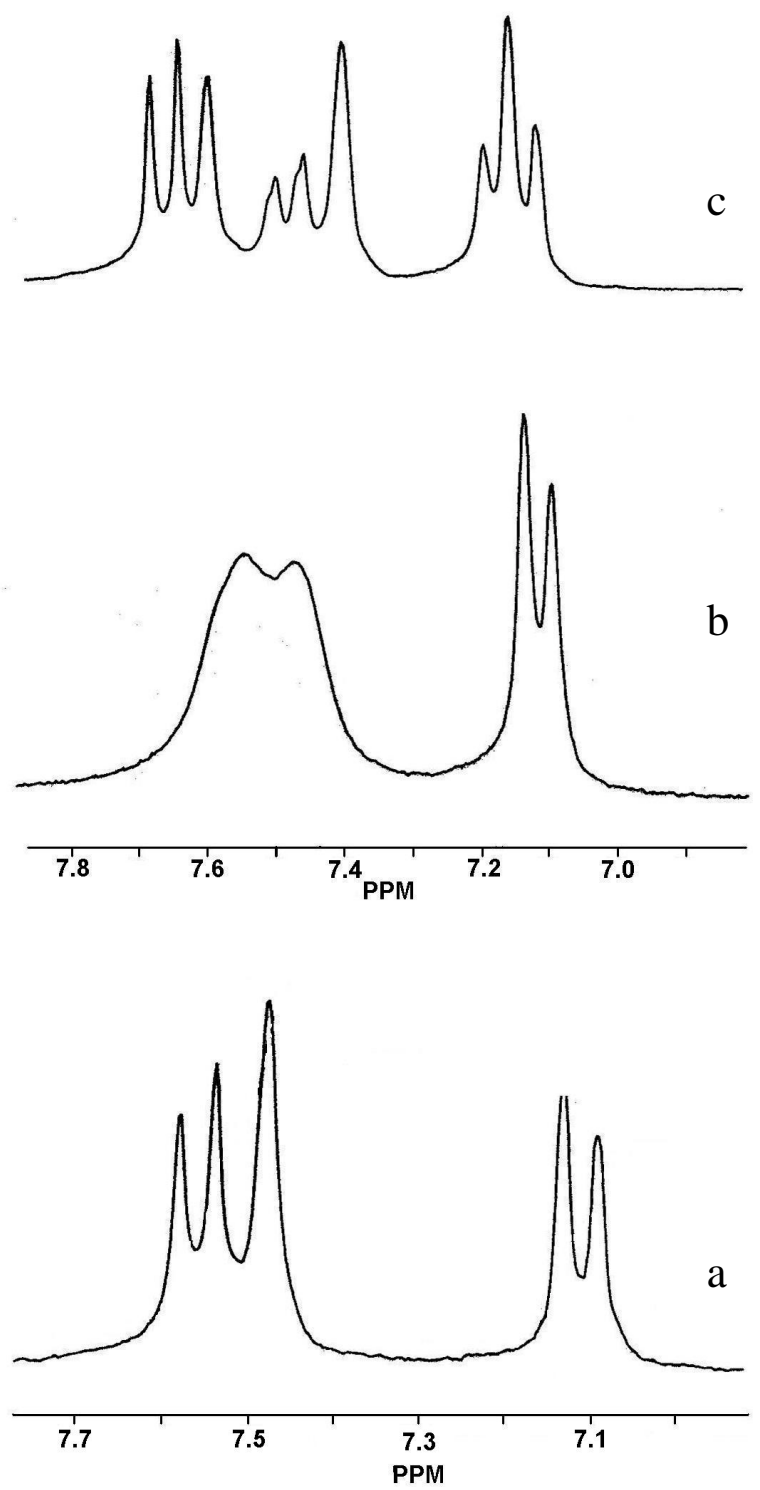

Figure 2. NMR spectra of compound 2 in DMSO- $\mathrm{d}_{6} / \mathrm{Me}_{2} \mathrm{CO}-\mathrm{d}_{6}$ at different temperatures. Evolution of the aromatic protons at (a) 308 K; (b) $297 \mathrm{~K}$; (c) $258 \mathrm{~K}$

to $\mathrm{H}_{\mathrm{c}}$. The other aromatic protons appeared as a broad signal centered at $\delta$ 7.72. The $\mathrm{H}_{\mathrm{c}}$ doublet coalesced at $282 \mathrm{~K}$ (Figure $3 \mathrm{~b}$ ). At this temperature two broad signals due to $\mathrm{H}_{\mathrm{a}}$ and $\mathrm{H}_{\mathrm{b}}$ were also seen. Finally at $267 \mathrm{~K}$ (Figure $3 \mathrm{c}$ ), the $\mathrm{H}_{\mathrm{c}}$ protons split into two adjacent doublets of unequal intensities, centered at $\delta 7.37$ and 7.32, whereas the $\mathrm{H}_{\mathrm{a}}$ protons split into two singlets, due to nonequivalent $\mathrm{H}_{\mathrm{a}}$ and $\mathrm{H}_{\mathrm{a}}$, at $\delta 7.62$ and 7.85. These signals were partially superimposed onto two other doublets, centered at $\delta 7.64$ and 7.83, which arose from the two nonequivalent $\mathrm{H}_{\mathrm{b}}$ and $\mathrm{H}_{\mathrm{b}}$, protons.

The spectra of the dimethoxybis-benzimidazole (4) at different temperatures are shown in Figure 4. At $318 \mathrm{~K}$, the
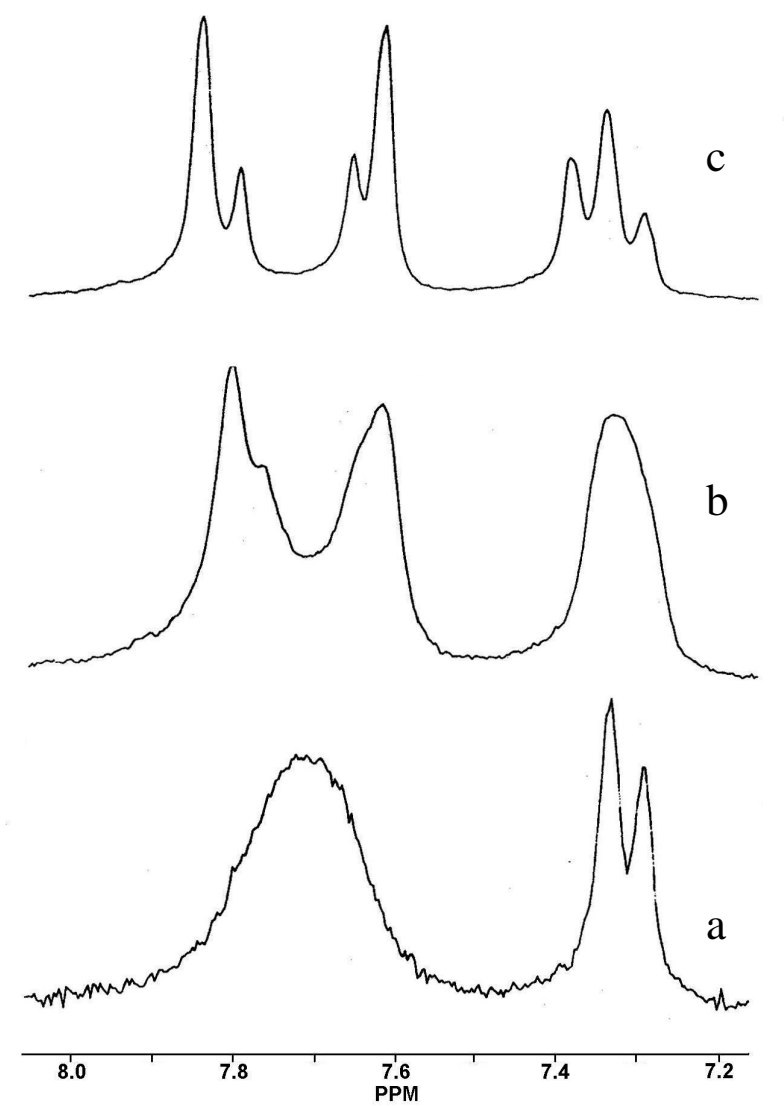

Figure 3. NMR spectra of compound 3 in DMSO- $\mathrm{d}_{6} / \mathrm{Me}_{2} \mathrm{CO}-\mathrm{d}_{6}$ at different temperatures. Evolution of the aromatic protons at (a) 297 $\mathrm{K}$; (b) $282 \mathrm{~K}$; (c) $267 \mathrm{~K}$

aromatic protons appeared as three different signals, a doublet of doublets centered at $\delta 6.89$ for $\mathrm{H}_{\mathrm{c}}$, a doublet, centered at $\delta 7.14$ for $\mathrm{H}_{\mathrm{a}}$ and a doublet at $\delta 7.55$ for $\mathrm{H}_{\mathrm{b}}$. The $\mathrm{H}_{\mathrm{a}}$ doublet coalesced at $280 \mathrm{~K}$, and the $\mathrm{H}_{\mathrm{b}}$ doublet at $278 \mathrm{~K}$. Under conditions of slow exchange ( $\mathrm{T}=248 \mathrm{~K}$ ), two adjacent doublets of unequal intensity, at $\delta 6.92$ and 6.96, arising from $\mathrm{H}_{\mathrm{c}}$ and $\mathrm{H}_{\mathrm{c}}$, could be seen, together with two unequal singlets at $\delta 7.07$ and 7.29, due to the nonequivalent $\mathrm{H}_{\mathrm{a}}$ and $\mathrm{H}_{\mathrm{a}}$, protons. Finally, the $\mathrm{H}_{\mathrm{b}}$ and $\mathrm{H}_{\mathrm{b}}$, signals appeared as two unequal doublets, centered at $\delta 7.68$ and 7.51. An approximate equilibrium distribution of $1: 2.5$ between the two tautomers could be estimated by integration of the two $\mathrm{H}_{\mathrm{a}}$ and $\mathrm{H}_{\mathrm{a}}$, singlets in Figure 4c.

The spectral analysis of tautomerism of the 4(7), $4^{\prime}\left(7^{\prime}\right)$ dimethylbis-benzimidazole (5) was complicated by the poorly resolved signals of the two tautomers even at a rather low temperature $\left(228 \mathrm{~K}\right.$ ) (Figure 5). At $297 \mathrm{~K}_{\text {the }} \mathrm{H}_{\mathrm{c}}$ proton was observed as a doublet, at $\delta 7.07$, together with the $\mathrm{H}_{\mathrm{b}}$ (triplet at $\delta 7.18$ ) and $\mathrm{H}_{\mathrm{a}}$ (doublet at $\delta 7.50$ ) nuclei. The coalescence of the latter doublet took place at $251 \mathrm{~K}$. Decreasing the temperature to $228 \mathrm{~K}$ led to the appearance 

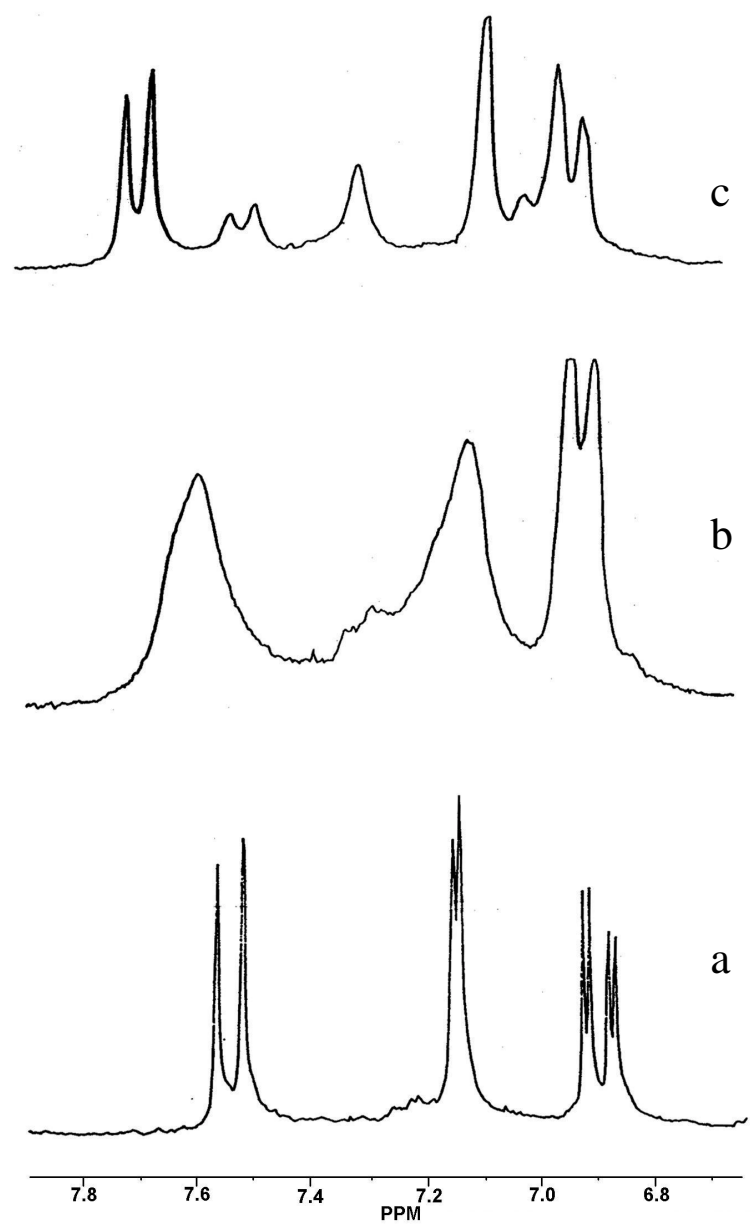

Figure 4. NMR spectra of compound 4 in DMSO- $\mathrm{d}_{6} / \mathrm{Me}_{2} \mathrm{CO}-\mathrm{d}_{6}$ at different temperatures. Evolution of the aromatic protons at (a) 318 $\mathrm{K}$; (b) $278 \mathrm{~K}$; (c) $248 \mathrm{~K}$

of two poorly resolved doublets, around $\delta 7.46$ and 7.64, suggesting, because of the unequal integration of the signals, slightly different populations for both tautomers. Unfortunately, the temperature of the sample could not be further lowered, thus precluding the exact determination of the chemical shift difference between the two signals.

The energy barrier, in $\mathrm{kJ} \mathrm{mol}^{-1}$, for tautomer interconversion of compounds $\mathbf{1}$ and $\mathbf{2}$ was determined with the aid of equation (1), which applies to equilibria between equally populated species. ${ }^{13}$
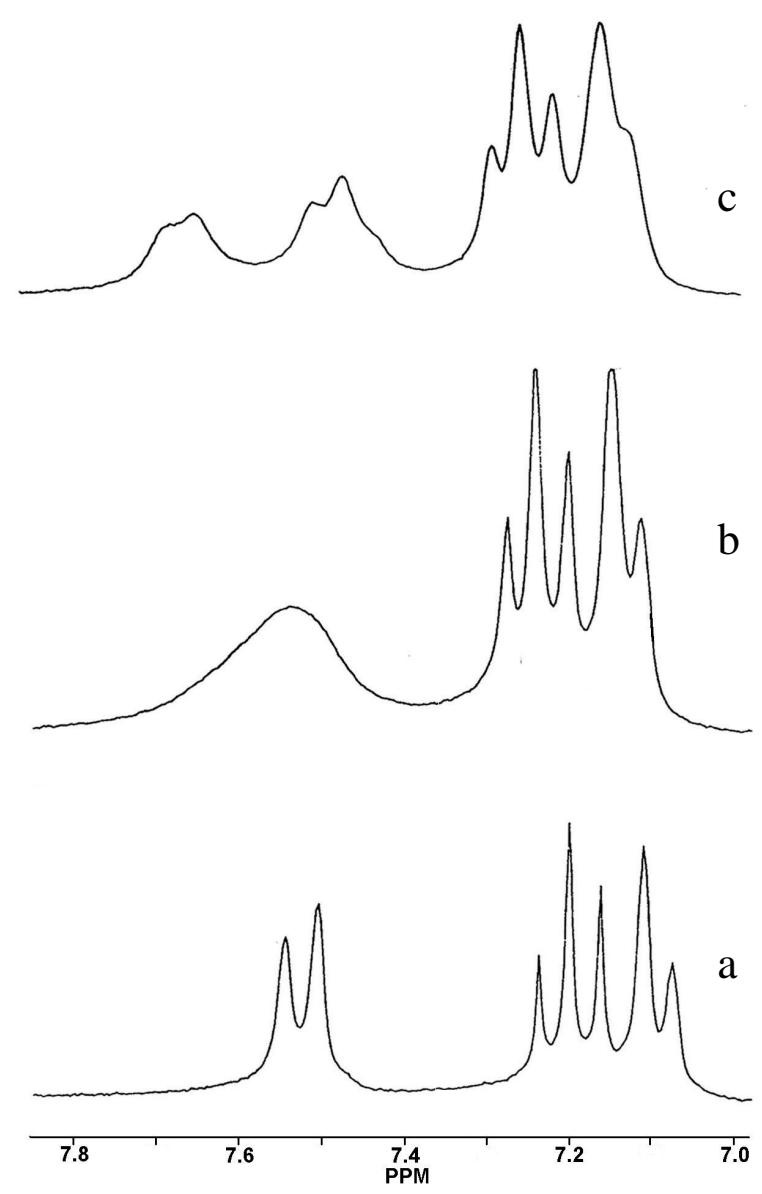

Figure 5. NMR spectra of compound 5 in DMSO- $\mathrm{d}_{6} / \mathrm{Me}_{2} \mathrm{CO}-\mathrm{d}_{6}$ at different temperatures. Evolution of the aromatic protons at (a) 297 $\mathrm{K}$; (b) $251 \mathrm{~K}$; (c) $228 \mathrm{~K}$

$\Delta \mathrm{G}^{\neq}=1.91 \times 10^{-2} \mathrm{~T}_{\mathrm{c}}\left(9.97+\log \mathrm{T}_{\mathrm{c}} / \Delta v_{\mathrm{c}}\right)$

where $\mathrm{T}_{\mathrm{c}}$ is the coalescence temperature and $\Delta v_{\mathrm{c}}$ is the chemical shift difference between two slowly exchanging signals. In the case of compound 2 this barrier was calculated for the two proton pairs $\mathrm{H}_{\mathrm{b}} / \mathrm{H}_{\mathrm{b}}$, and $\mathrm{H}_{\mathrm{c}} / \mathrm{H}_{\mathrm{c}}$. The results for bis-benzimidazoles $\mathbf{1}$ and $\mathbf{2}$ are given in the Table 1.

Inspection of the spectra obtained under conditions of slow exchange for compounds 3 and especially 4 suggested uneven equilibria between the corresponding tautomers.<smiles></smiles>

(5a)

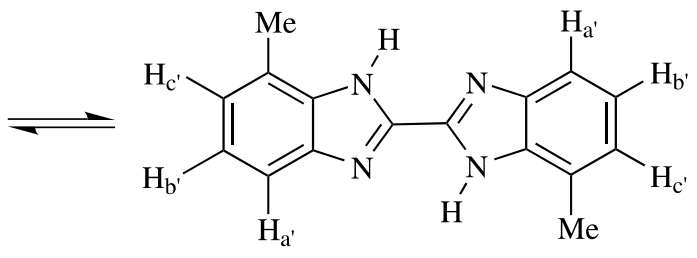

(5b)

Scheme 4. 
Table 1. Experimental and theoretical (gas-phase) calculations of tautomeric stability and interconversion energies for bis-benzimidazoles 1-5

\begin{tabular}{|c|c|c|c|}
\hline Compound & $\begin{array}{l}\text { Experimental free energy of } \\
\text { activation for tautomerism } \\
\mathrm{kJ} \mathrm{mol}^{-1}\end{array}$ & $\begin{array}{l}\text { Calculated difference } \\
\text { between heats of formation } \\
\text { of tautomers, } \mathrm{kJ} \mathrm{mol}^{-1}\end{array}$ & $\begin{array}{l}\text { Calculated energy } \\
\text { barriers for tautomerism, } \\
\mathrm{kJ} \mathrm{mol}^{-1}\end{array}$ \\
\hline 1 & 63 & 0 & 185 \\
\hline 2 & $64 \pm 1^{b}$ & 0.5 & 188 \\
\hline 3 & $61.5 \pm 0.5^{\mathrm{c}} ; 63^{\mathrm{d}}$ & 0.6 & 188 \\
\hline 4 & $58^{\mathrm{e}} ; 60^{\mathrm{e}}$ & 3 & 185 \\
\hline 5 & $<52 ;<53$ & 0.9 & 189 \\
\hline
\end{tabular}

${ }^{a}$ two values are given in the case of unequal tautomer populations in equilibrium; ${ }^{\mathrm{b}}$ average of two values corresponding to the $\mathrm{H}_{\mathrm{b}} / \mathrm{H}_{\mathrm{b}}$, and the $\mathrm{H}_{\mathrm{c}} / \mathrm{H}_{\mathrm{c}}$, pairs; ${ }^{c}$ average of two values corresponding to the $\mathrm{H}_{\mathrm{a}} / \mathrm{H}_{\mathrm{a}}$, and the $\mathrm{H}_{\mathrm{c}} / \mathrm{H}_{\mathrm{c}}$, pairs; ${ }^{\mathrm{d}}$ same value, corresponding to the $\mathrm{H}_{\mathrm{a}} / \mathrm{H}_{\mathrm{a}}$, and the $\mathrm{H}_{\mathrm{b}} / \mathrm{H}_{\mathrm{b}}$, pairs; ${ }^{e}$ same value, corresponding to the $\mathrm{H}_{\mathrm{a}} / \mathrm{H}_{\mathrm{a}}$, and the $\mathrm{H}_{\mathrm{b}} / \mathrm{H}_{\mathrm{b}}$, pairs

For the bis-benzimidazole $\mathbf{3}$, the ratio between the concentrations of the two conformers in equilibrium was roughly estimated as $2: 3$, based on the integrations of the two $\mathrm{H}_{\mathrm{c}}$ and $\mathrm{H}_{\mathrm{c}}$, doublets at $\delta 7.32$ and 7.37 (Figure 3c). For compound 4 , as stated above, this ratio was approximately $1: 2$.

In the case of compound $\mathbf{5}$, the two signals with unequal intensities around $\delta 7.50$ and 7.70 (Figure 5c) also suggested an equilibrium between the corresponding tautomers departing from a 1:1 ratio. Integration of the two unresolved signals yielded an approximate ratio of 2:3. Since conditions of slow exchange with well resolved signals could not be attained, the values obtained for the barrier energies and the equilibrium ratio were very approximate. The $\Delta v_{\mathrm{c}}$ employed in the calculations, obtained from the spectrum at $228 \mathrm{~K}$, is probably smaller than the correct value for the chemical shift difference between the two well resolved doublets under conditions of slow exchange. In consequence, the calculated energies should be taken as upper limit values for the interconversion barrier.

The energy barriers for bis-benzimidazoles 3, 4 and 5 were estimated by following the method for obtaining $\Delta \mathrm{G}^{\neq}$ by the coalescence of unequal doublets. The free energies of activation, in $\mathrm{kJ} \mathrm{mol}^{-1}$, are given by equations (2) and (3), ${ }^{14}$

$$
\begin{aligned}
\Delta \mathrm{G}_{\mathrm{A}}^{\neq}=19.12 \mathrm{~T}_{\mathrm{c}}[10.62+\log \mathrm{X} / 2 \pi & (1-\Delta \mathrm{P})+ \\
& \left.\log \mathrm{T}_{\mathrm{c}} / \Delta v_{\mathrm{c}}\right] \\
\Delta \mathrm{G}_{\mathrm{B}}^{\neq}=19.12 \mathrm{~T}_{\mathrm{c}}[10.62+\log \mathrm{X} / 2 \pi( & (1+\Delta \mathrm{P})+ \\
& \left.\log \mathrm{T}_{\mathrm{c}} / \Delta v_{\mathrm{c}}\right]
\end{aligned}
$$

where $\mathrm{X}$ is a function of the $\Delta v_{\mathrm{c}}$ and the lifetime $\tau$ of the process and $\Delta \mathrm{P}$ is the difference between the relative concentrations of the two species $\mathrm{P}_{\mathrm{A}}$ and $\mathrm{P}_{\mathrm{B}}$ in equilibrium. The terms $\log \mathrm{X} / 2 \pi(1-\Delta \mathrm{P})$ and $\log \mathrm{X} / 2 \pi(1+\Delta \mathrm{P})$ were obtained graphically ${ }^{14}$ from the values of $\Delta \mathrm{P}$ of $0.2,0.43$ and 0.2 for compounds $\mathbf{3 , 4}$ and $\mathbf{5}$ respectively. The corresponding energy barriers, calculated for two different proton pairs in the case of compounds $\mathbf{3}$ and $\mathbf{4}$, are given in Table 1 .

Before examining the results of Table 1, we should discuss all approximations made in our analysis, and the resulting errors in our estimates. In the preceding analysis we assumed that all chemical shifts were temperature independent, which was not strictly correct in some instances. The errors in the sample temperatures $\left(\Delta \mathrm{T}_{\mathrm{c}}= \pm 1 \mathrm{~K}\right)$ were also responsible for deviations in the calculated energy barriers. We calculated these deviations from the relationship $\Delta \Delta \mathrm{G}^{\neq}=\left(\partial \Delta \mathrm{G}^{\neq} / \partial \mathrm{T}_{\mathrm{c}}\right)_{\Delta v} \cdot \Delta \mathrm{T}_{\mathrm{c}}+\left(\partial \Delta \mathrm{G}^{\neq} /\right.$ $\left.\partial \Delta \mathrm{n}_{\mathrm{c}}\right)_{\mathrm{T}} . \Delta \Delta v_{\mathrm{c}}$, and obtained values in the $0.2-2.0 \mathrm{~kJ} \mathrm{~mol}^{-1}$ range, with a $0.9 \mathrm{~kJ} \mathrm{~mol}^{-1}$ average deviation. We therefore assumed our experimental energy barriers to be accurate to $1 \mathrm{~kJ} \mathrm{~mol}^{-1}$.

\section{Theoretical calculations}

The relative stability of each pair of tautomers of compounds 1-5 was theoretically investigated by comparison of their heats of formation, calculated with the PM3 method. Compound 4 yielded the greatest difference $\left(3 \mathrm{~kJ} \mathrm{~mol}^{-1}\right)$ between the $\Delta \mathrm{H}_{\mathrm{f}}$ values of both tautomers, with the structure of $\mathbf{4 a}$ being the more stable of the two. For the other bis-benzimidazoles this difference<smiles>COc1ccc2nc(-c3nc4ccc(OC)cc4[nH]3)[nH]c2c1</smiles><smiles>C/N=C1\C=CC(=[O+]C)/C(=C2/Nc3ccc(OC)cc3N2)N1</smiles>

(4a)

Scheme 5. 
was never greater than $1 \mathrm{~kJ} \mathrm{~mol}^{-1}$. These results should be regarded with caution, as they apply to the gas-phase heats of formation of the tautomers in equilibrium. Nevertheless, they agree with the observation that the estimated equilibrium ratio was greatest for compound $\mathbf{4}$, with smaller, similar values for compounds $\mathbf{3}$ and $\mathbf{5}$.

We also estimated the energy barriers for tautomerism of all bis-benzimidazoles by calculation of the energy differences between ground and transition states in each case. For all compounds calculations converged to transition state structures very similar to that previously calculated for the unsubstituted 2,2'-bis-benzimidazole. ${ }^{1}$ In cases where two TS structures were possible, we always considered the more stable one. Our theoretical results are summarized in Tables 1 and 2.

Table 2. Calculated energy barriers, $\mathrm{kJ} \mathrm{mol}^{-1}$, for the interconversion of bis-benzimidazoles 1-5, in solution

\begin{tabular}{crcc}
\hline Compound & Acetone $^{\mathrm{a}}$ & DMSO $^{\mathrm{b}}$ & DMSO:acetone $(1: 4)^{\mathrm{c}}$ \\
\hline $\mathbf{1}$ & 175.35 & 175.01 & 174.96 \\
$\mathbf{2}$ & 182.75 & 182.17 & 182.36 \\
$\mathbf{3}$ & 182.37 & 182.17 & 182.06 \\
$\mathbf{4}$ & 181.37 & 181.24 & 181.32 \\
$\mathbf{5}$ & 178.75 & 178.00 & 178.32 \\
\hline${ }^{\mathrm{a}} \varepsilon=21.01$, ref. $15 ;{ }^{\mathrm{b}} \varepsilon=46.60$, ref. $15 ;{ }^{\mathrm{c}} \varepsilon_{\text {solution }}=\left(\varepsilon_{\text {DMso }} \times \chi_{\text {DMSO }}\right)+$ \\
$\left(\varepsilon_{\text {acetone }} \times \chi_{\text {acetone }}\right)=26.26$, where $\chi$ means molar fraction, ref.16
\end{tabular}

\section{Discussion}

The relative stabilities of all tautomer pairs 1-5 were reproduced reasonably well by theoretical calculations, as can be seen by inspection of Table 1. Dimethoxybisbenzimidazole 4 exhibited the greatest difference between the heats of formation of its tautomers, in agreement with the experiment. The reason for the greater stability of tautomer 4a may be sought in the contribution of the canonical structure given below to the resonance hybrid. A contribution of this nature is not possible for the other tautomer, where the electron-donating OMe substituent is para to the -NH- imidazole group.

One cannot expect the calculated energy barriers for tautomerism to yield values close to the corresponding experimental free energies. In the first case we are dealing with enthalpic values in the gas phase, whereas the second values are free energy variations in solution. Our calculated values fall within the range of those calculated with the PM3 method for the tautomerism of oxalamidine and six oxalamidine analogs,${ }^{5}$ for which reliable evidence exists for a mechanism involving a stepwise process and zwitterionic intermediates. ${ }^{6}$ The large differences between the experimental energy barriers and the theoretically calculated transition energies reported for those systems were reproduced in our study on the tautomerization of 2,2'-bis-benzimidazole ${ }^{1}$ and in the present work. The absolute values of the transition energies obtained theoretically are therefore of little diagnostic value for us. What should concern us here are the trends observed in these calculated energies. Inspection of Table 1 shows that the calculated energy barriers are practically independent of the nature of the substituents. This was also observed in our calculations when solvent corrections were taken into account through the COSMO option (Table 2). Calculations employing the medium dielectric constant, $\varepsilon$, of acetone, DMSO and DMSO-acetone (1:4, v/v) yielded smaller energy barriers, but the relative constancy of the new values was maintained (Table 2). This constancy, irrespective of the nature of the substituent, is also observed in the experimental values listed in Table 1, with the possible exception of compound 5. Thus, the introduction of two symmetrical electron-withdrawing $\mathrm{Cl}$ substituents in $\mathbf{3}$, or of two electron-donating methyl substituents in 2 led to energy barriers in DMSO- $\mathrm{d}_{6} /$ $\mathrm{Me}_{2} \mathrm{CO}-\mathrm{d}_{6}$ rather close to those of the unsubstituted 2,2'bis-benzimidazole in DMSO- $\mathrm{d}_{6}\left(67 \mathrm{~kJ} \mathrm{~mol}^{-1}\right) .{ }^{1}$

This lack of sensitivity of the energy barriers to the nature of the substituents is in agreement with the postulated mechanism of tautomerization, which involves a two-step process with a zwitterionic intermediate..$^{1,4,6}$

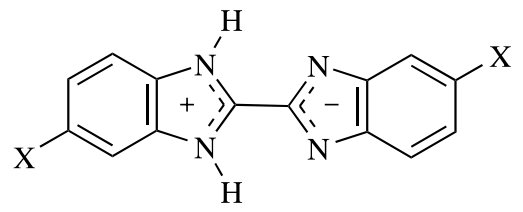

Scheme 6.

Thus, for a transition state with an incipient zwitterionic character, the effects of the two symmetrical substituents $\mathrm{X}$ on the benzimidazolium and benzimidazolide moieties should oppose and, at least partially, cancel each other.

Compound 5 exhibited the lowest experimental energy barrier of the series but the values obtained should be regarded with caution. As mentioned above, these values should be taken as upper limits for the true energy barriers, which could not be estimated with the same degree of accuracy as those for the other bis-benzimidazoles 1-4. Nevertheless, the results indicate that compound $\mathbf{5}$ tautomerizes faster than the other bis-benzimidazoles 1-4. One possible explanation for this easier tautomerization of 5 may be sought in the proximity of the 4(7), 4'(7')- 
<smiles>Cc1cccc2nc3n(c12)C1[13CH]3c2nc3cccc(C)c3n21</smiles>

Scheme 7.

methyl substituents to the migrating protons. Proton transfer to form the zwitterionic intermediate should relieve the steric compression of the molecule, by pushing the hydrogen atom away from the neighbouring methyl group.

In the above discussion we have not taken into account the role of the solvent in the tautomeric process. Kinetic studies carried out with two bicyclic oxalamidines in deuterated methylcyclohexane and acetonitrile have shown that they tautomerize in both solvents via the same two-step process herein postulated. ${ }^{6}$ The process is facilitated in the more polar solvent, in agreement with the development of a transition state with an incipient zwitterionic character.

In our case, although it is also reasonable to assume some degree of solvent participation in the tautomeric proton shift by the strongly donor DMSO molecules, our calculations for bis-benzimidazoles 1-5 in solutions of varying dielectric constant show values which are similar for the energy barriers for all the solvents, Table 2, but which differ greatly from the experimental ones. The fact that changes in the dielectric constant of the medium do not cause a significant effect in the energy barriers may be explained by analysis of the canonical structures which contribute to the resonance hybrid of the zwitterionic intermediate. Estimates show that the electron density of the nitrogen atoms involved in the proton transfer does not vary significantly in the reaction coordinate, being in the range 5.22 to 5.34. This is also expected if one considers the neutral canonical form that contributes to the zwitterionic hybrid stabilization. In spite of the apparent absence of solvent contribution to the process, we do not think that the mechanism of tautomerism of bis-benzimidazoles 1-5 in deuterated DMSO / $\mathrm{Me}_{2} \mathrm{CO}$ is qualitatively different from that of the analogous oxalamidine systems in polar media. Free energy barriers for different bicyclic oxalamidines in methylcyclohexane and acetonitrile, tautomerizing via stepwise, two single-proton transfers, fall within the range $40-50 \mathrm{~kJ} \mathrm{~mol}^{-1}$, with Arrhenius activation energies of about $60 \mathrm{~kJ} \mathrm{~mol}^{-1}{ }^{6}$ We have obtained similar barrier values for the tautomerism of 2,2-bis-benzimidazole in DMSO-d 6 (67 kJ mol $\left.{ }^{-1}\right)$ and of bis-benzimidazoles 1-5 in DMSO- $\mathrm{d}_{6} / \mathrm{Me}_{2} \mathrm{CO}-\mathrm{d}_{6}\left(50-65 \mathrm{~kJ} \mathrm{~mol}^{-1}\right)$. By contrast, a different mechanism, such as the concerted double proton transfer postulated for the tautomerism of indigodiimine in $\mathrm{CDCl}_{3}$ / $\mathrm{CDCl}_{2} \mathrm{~F}-\mathrm{CDClF}_{2}$, is associated with a very different Arrhenius activation energy of only $23 \mathrm{~kJ} \mathrm{~mol}^{-1}$.

\section{Conclusion}

The influence of symmetrical substituents on the tautomerism of substituted 2,2'-bis-benzimidazoles was studied by ${ }^{1} \mathrm{H}$ NMR spectroscopy at different temperatures, for compounds 1-5. In the case of compounds 3-5, low temperature spectra suggested unequal tautomer populations in equilibrium. This observation is in reasonable agreement with semi-empirical calculations in the gas phase and in solution for these systems, specially for compound 4. The observed small dependence of the tautomeric energy barriers on the nature of the substituents was rationalized by a mechanism of tautomerism, which involves a zwitterionic intermediate. The effects of the symmetrical substituents in stabilizing/destabilizing the zwitterionic moieties of the transition state tend to cancel out, with the net result that the energy barrier for tautomerism is practically independent of the nature of the substituent. The smaller energy barrier for the tautomerism of bis-benzimidazole 5 did not contradict this view, which was based on electronic effects only. The greater ease of tautomerism of $\mathbf{5}$ was interpreted as arising from steric relief of the solvated molecule in the transition state to form the zwitterionic intermediate.

\section{Acknowledgements}

We are grateful to CNPq and PRONEX, in Brazil, and to Conicyt, in Chile, for supporting this work.

\section{References}

1. Zucco, C.; Dall'Oglio, E.; Salmoria, G.V.; Gallardo, H.; Neves, A.; Rezende, M.C.; J. Phys. Org. Chem. 1998, 11, 411.

2. Dall'Oglio. E.; Rezende, M.C.; Zucco, C.; Tetrahedron Lett. 1996, 37, 5265.

3. Rezende, M.C.; Marques, C.A.; Dall'Oglio, E.; Zucco, C.; Liebigs Ann./Recueil 1997, 925.

4. Scherer, G.; Limbach, H.-H.; J. Am. Chem. Soc. 1989, 111, 5946.

5. Scherer, G.; Limbach, H.-H. Croat. Chem. Acta 1994, 67, 431.

6. Scherer, G.; Limbach, H.-H.; J. Am. Chem. Soc. 1994, 116, 1230 .

7. Thoburn, J.D.; Luettke, W.; Benedict, C.; Limbach, H.-H.; J. Am. Chem. Soc. 1996, 118, 12459. 
8. Raczynska, E.D.; Anal. Chim. Acta 1997, 348, 431.

9. Li, G.-S.; Ruiz-López, M.F.; Maigret, B.; J. Phys. Chem. A 1997, 101, 7885.

10. Raczynska, E.D.; J. Chem. Res. Synop. 1998, 704.

11. Dall'Oglio, E.; Rezende, M.C.; Zucco, C.; Synth. Commun. 2001, 31, 607.

12. MOPAC 7.0, Fujitsu Corporation, Cambridge, USA, 1993.

13. Gil, V.M.S.; Geraldes, C.F.G.C.; Ressonância Magnética Nuclear, Fundação Calouste Gulbenkian: Lisboa, 1987, p. 514.
14. Shanan-Atidi, H.; Bar-Eli, K.H.; J. Phys. Chem. 1970, 74, 961.

15. Dean, J. A.; Lange's Handbook of Chemistry, Mc Graw-Hill Book Company: New York, 1985.

16. Garg, S. K.; Smyth, C. P.; J. Phys. Chem. 1965, 69, 1294.

Received: November 1, 2000

Published on the web: March 12, 2002 